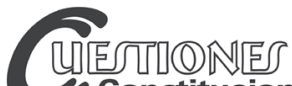 \\ Constitucionales
}

Revista Mexicana de Derecho Constitucional

Núm. 27, julio-diciembre 2012

\section{GARZÓN, UN JUEZ ANTE EL SUPREMO}

\section{Abraham BARRERO ORTEGA*}

El pasado febrero, la Sala Penal del Tribunal Supremo dictó dos sentencias $^{1}$ relativas a sendas querellas interpuestas contra el juez de la Audiencia Nacional: Baltasar Garzón. Dos querellas en las que se imputaba a Garzón el mismo delito de prevaricación, una al hilo del caso de las escuchas de Gürtel y la otra al hilo de los llamados juicios de la verdad. Y dos sentencias con un resultado diferente. La primera, condenatoria, concluye que Garzón dictó una sentencia injusta a sabiendas. La segunda, absolutoria, considera que dictó una resolución errónea, pero no prevaricadora.

En lo que sigue intentaré aportar algunas reflexiones nacidas, de un modo inmediato, de la lectura de las dos sentencias del Tribunal Supremo. Las consideraciones del Supremo, y algunas mías al hilo de las suyas, serán las que queden expuestas aquí. Aclaro, en todo caso, que mi valoración será una valoración exclusivamente jurídica, dejando de lado otro tipo de circunstancias. No diré que tanto en las querellas como en las dos sentencias que las resuelven no hayan pesado otros factores ajenos al derecho, pero intentaré ceñir mi enjuiciamiento al ámbito jurídico. Mi valoración parte, asimismo, del respeto y la consideración que obviamente merece todo pronunciamiento del alto tribunal. Se trata de dos sentencias polémicas, complejas, pero en las que se aprecia un esfuerzo argumentativo incontestable. Nótese, además, que la sentencia condenatoria es una sentencia dictada por unanimidad, sin votos particulares, está suscrita por los siete magistrados de la Sala Segunda.

Ahora bien, el respeto que merecen las sentencias del Supremo no significa que resulte ilegítimo seguir reflexionando acerca de las razones por las que se condena a Garzón y se le expulsa de la función judicial.

* Profesor titular de Derecho Constitucional en la Universidad de Sevilla.

1 Sentencias del 9 y 27 de febrero de 2012. 
Aunque sólo sea por interés intelectual, merece la pena esa reflexión. Adelanto que no comparto la sentencia condenatoria. Entiendo que los mismos argumentos que llevaron al Supremo a no apreciar prevaricación en el caso de los juicios de la verdad deberían haber conducido a no apreciarla en el caso de las escuchas de Gürtel. Hay una cierta contradicción entre las dos sentencias. La segunda rebaja, por así decir, el listón de la prevaricación de la primera.

Y todo ello dejando igualmente claro desde el principio que, en mi opinión, el juez Garzón se equivocó gravemente en uno y otro caso. Interpretó erróneamente el ordenamiento jurídico, el derecho vigente, vulnerando incluso derechos fundamentales en la instrucción de la causa Gürtel. Realizó, al menos en este supuesto, una interpretación de la legalidad contraria al derecho de defensa consagrado en el artículo 24.2 de la Constitución Española (en adelante CE). Pero de ahí a apreciar prevaricación hay un abismo. Ni en uno ni en otro caso se daban los elementos para apreciar que Garzón dictó intencionadamente una resolución injusta.

\section{LA PREVARICACIÓN JUDICIAL}

Como quiera que sea, antes de entrar en el análisis de las sentencias del Supremo y a fin de enmarcar mejor su contexto, acaso no resulte ocioso realizar algunas precisiones elementales en torno al tipo penal de la prevaricación judicial. ¿ ¿Qué se entiende por prevaricación? ¿Qué requisitos han de darse para entender que un juez prevarica? ¿Qué dificultades plantea la interpretación de este tipo penal?

Los querellantes imputaban a Garzón, en efecto, haber dictado a sabiendas una resolución injusta (artículo 446 del CP). La injusticia es el elemento objetivo del tipo delictivo. Y la valoración de esa injusticia debe realizarse en función del caso concreto, de las circunstancias de cada supuesto, de cada resolución o sentencia judicial. No es fácil apreciar esa injusticia. Primero, porque los jueces pueden valorar libremente la prueba (artículos 741 de la LECrim y 218 y 316 de la LEC) y, segundo, porque el sistema de recursos dificulta enormemente la persecución del delito. El juez pueda equivocarse, pero esa equivocación puede ser

2 Sigo en adelante casi exclusivamente a Juanes Peces, A., "La prevaricación judicial”, Cuadernos de Derecho Judicial, núm. 16, 2005, pp. 229-256 y García Arán, M., La prevaricación judicial, Madrid, Tecnos, 1990. 
corregida a través del sistema de recursos. Esto es normal y no por ello puede afirmarse que en todo caso en que un juez se confunda existe prevaricación.

El problema, en último extremo, se traslada al ámbito de la interpretación jurídica, debiendo entenderse como injusta no la interpretación errónea del derecho, no la equivocación, sino la interpretación injustificable en el plano teórico. Incurrirá en prevaricación el juez que interprete la ley al margen de las reglas tradicionales para la interpretación jurídica, que se aparte completamente de las reglas de interpretación comúnmente aceptadas. Despreciando esas reglas, prevarica el juez que interpreta la ley de forma extravagante, saliéndose de lo común. La resolución tiene que ser irracional. Ha de probarse la absoluta notoriedad en la injusticia, faltando tal elemento cuando se trata de apreciaciones que en uno u otro grado son discutibles en derecho; la resolución ha de encontrarse patente, notoria e incuestionablemente enfrentada al ordenamiento jurídico. Sea como fuere, debe admitirse que no es fácil apreciar la diferencia entre una interpretación errónea, mal motivada o insuficientemente motivada y una interpretación opuesta a la razón, de ningún modo justificable teóricamente. No es fácil trazar la línea divisoria.

Y si difícil resulta apreciar el elemento objetivo, la injusticia de la resolución, no digamos el elemento subjetivo, el que la resolución injusta sea dictada a sabiendas. O sea, es preciso que el juez sepa y le conste que la resolución que dicta es injusta por contraria a la ley y que a pesar de ello la dicte conscientemente. La conducta típica exige el dolo directo. Debe existir plena conciencia del carácter injusto de la resolución o una clara conciencia de la ilegalidad y arbitrariedad. Con lo cual el juez traiciona su función de aplicador de la ley; quiebra su legitimidad. El juez aplica su criterio personal por encima de la ley; se escuda en la ley para imponer su voluntad. El recurso a la ley esconde un capricho personal. El juez no se equivoca, se quiere equivocar. Impone sus convicciones al margen de la realidad objetiva del procedimiento o del contenido de las leyes que el juez conoce o debiera conocer.

Sin perder de vista cuanto antecede, ¿cómo aplica el Tribunal Supremo el tipo penal de la prevaricación en el caso de las escuchas de Gürtel y en el de los juicios de la verdad? ¿Por qué estima que el juez Garzón prevaricó en un asunto y no en el otro? Intentaré ir al núcleo de la argumentación, separando el grano de la paja. 


\section{LAS ESCUCHAS DE GÜRTEL}

Recuérdese que, en el caso Gürtel, Garzón ordenó escuchar las conversaciones mantenidas en prisión por los imputados con sus abogados. La intervención de las comunicaciones se basó en la hipótesis de que los letrados pudieran hacer de "enlace" con la organización delictiva. Además, Garzón autorizó unas escuchas indiscriminadas, destinada a la generalidad de los abogados, tanto a los que se encontrasen personados en la causa como a los que en el futuro pudieran asistir profesionalmente a los imputados. Ordenó la interceptación de las conversaciones no sólo con los abogados designados sino con cualquier otro que se pudiera designar — ni siquiera modificó su decisión, a pesar de que algunos imputados designaron otros abogados-, con lo que abrió una especie de causa general. Fundó las escuchas en el artículo 51.2 de la Ley Orgánica General Penitenciaria (en adelante LOGP), en virtud del cual "las comunicaciones de los internos con el abogado defensor o con el abogado expresamente llamado en relación con asuntos penales y con los procuradores que lo representen se celebrarán en departamentos apropiados y no podrán ser suspendidas o intervenidas salvo por orden de la autoridad judicial y en los supuestos de terrorismo".

El Tribunal Supremo, en atención a las concretas circunstancias del caso, considera que Garzón dictó intencionadamente una resolución injusta. En primer lugar, porque el artículo 51.2 de la LOGP sólo permite la intervención de las comunicaciones entre preso y abogado defensor en los supuestos de terrorismo por orden de la autoridad judicial. Es decir, en el curso de una investigación por delitos de terrorismo y previa autorización judicial motivada, en la que se expongan las razones que llevan o conducen a la interceptación con base en unos antecedentes de hecho y fundamentos jurídicos que la sustentan. Otras comunicaciones - las que mantenga el interno con terceras personas - podrán ser intervenidas motivadamente por el director del centro penitenciario, dando cuenta a continuación a la autoridad judicial. En cambio, las comunicaciones de los internos con sus legrados se someten a un régimen especial: la autorización de su intervención debe ser sólo dispuesta por la autoridad judicial en los supuestos de terrorismo. Un régimen legal más exigente habida cuenta de que está implicado el derecho de defensa, reconocido como derecho fundamental en el artículo 24.2 de la CE. Garzón, por tanto, quebrantó el tenor literal del artículo 51.2 de la LOGP. Los sospechosos 
no estaban siendo investigados por delitos de terrorismo. Los hechos que motivaron su ingreso en presión podrían ser constitutivos de un delito de blanqueo de capitales, defraudación fiscal, falsedad, cohecho, asociación ilícita y tráfico de influencias, como explícitamente admite el auto de intervención de las comunicaciones.

En segundo lugar, existe jurisprudencia del Tribunal Constitucional ${ }^{3} \mathrm{y}$ del Tribunal Supremo ${ }^{4}$ sobre este tema, por lo que Garzón sabía o debía saber que sólo se pueden interceptar las comunicaciones entre interno y abogado cuando concurran conjuntamente las dos condiciones mencionadas: indicios de terrorismo y resolución judicial motivada. La exigencia de ambas condiciones determina que la intervención no puede ser acordada por el director del establecimiento penitenciario y que, además, la autoridad judicial sólo podrá acordarla en supuestos de terrorismo. Garzón se debía a esa línea jurisprudencial consolidada.

Aun suponiendo, en tercer lugar, que se pueda interpretar que la ley ampara la intervención de las comunicaciones entre los internos y sus letrados más allá de los supuestos de terrorismo - y es mucho suponer-, el juez de instrucción, al acordar la interceptación, debe motivar el porqué. El juez, conforme al principio de proporcionalidad, debe expresar qué indicios de criminalidad respecto a los letrados justifican esa intervención; en qué medida el ejercicio de la defensa y la condición de abogado están siendo utilizadas para la comisión de delitos, y Garzón no lo hizo. Apoyó su resolución en la simple suposición de que los internos continuaban cometiendo delitos o en la mera posibilidad de que lo hicieran, con lo que limitó irregularmente el derecho a la defensa de los internos, pero también su derecho a no declarar, a la intimidad y hasta el secreto profesional de los letrados.

Garzón, en cuarto lugar, se equivocó a sabiendas. Lo sabía porque, en el auto por el que ordenó la interceptación de las conversaciones, incluyó expresamente la frase "previniendo el derecho de defensa". Esa cautela o precaución revela que conocía que su resolución afectaría a ese derecho fundamental. Los funcionarios de policía que intervinieron las comunicaciones le reclamaron aclaraciones del significado de ese inciso, sin que por su parte se dieran instrucciones para que los funcionarios no escucharan determinadas conversaciones o prescindieran de ellas en la elabo-

4 SSTS 245/1995, del 6 de marzo, y 538/1997, del 23 de abril. 
ración de los informes. Incluso el Ministerio Fiscal le reclamó la exclusión de las comunicaciones mantenidas con los letrados defensores. Y lo sabía, de otra parte, porque era imposible desconocer que esa cautela era ineficaz, no servía para preservar el derecho de defensa. Los funcionarios dependientes de la Dirección General de Instituciones Penitenciarias debían grabar las conversaciones; la policía judicial debía recibir las cintas, escuchar su contenido, transcribir lo relevante para la investigación y entregar la transcripción al juez instructor, y Garzón, finalmente, decidiría lo que afectaba al derecho de defensa. Pues bien, este procedimiento, dirigido en teoría a proteger la defensa de los internos, era infructuoso, inútil. No era más que una pura formalidad. Obviamente el contenido de las comunicaciones era escuchado y valorado por los funcionarios policiales. Y si los responsables de la investigación conocían o podían conocer el contenido de las conversaciones, la defensa perdía su sentido. Para esos funcionarios era una ventaja saber si el imputado había participado o no en los hechos, si una línea de investigación era acertada o poco provechosa, cuál era la estrategia defensiva, cuáles eran las pruebas que contradecían la prueba de cargo; esos funcionarios podrían aprovecharse de conocer las impresiones, dudas o preocupaciones del imputado o los consejos y las sugerencias de su abogado. Y, en fin, tampoco puede valorarse como medida preventiva la supresión por el juez instructor de algunos párrafos de las conversaciones intervenidas, ya que esa supresión sólo podía realizarse una vez que se hubiesen escuchado las conversaciones y, desde ese momento, el juez ya conocía el contenido.

\section{LOS JUICIOS DE LA VERDAD}

En el caso de los juicios de la verdad o de la memoria histórica, el Tribunal Supremo constata que Garzón inició y prolongó unas diligencias sobre las desapariciones del franquismo atribuyendo a personas fallecidas delitos que habían prescrito, estaban amnistiados y que, además, no eran competencia de la Audiencia Nacional. No obstante, el Tribunal Supremo estima que no prevaricó. No hay elementos para concluir que su interpretación de la legalidad careciera de toda explicación razonable, es decir, fuese a todas luces contraria a derecho. El Supremo aprecia incorrección interpretativa, pero no que Garzón se separase del ordenamiento 
jurídico de una manera palmaria y evidente, de tal modo que su resolución pudiera verse como manifiestamente injusta.

Erró en la calificación de los hechos - delito permanente de detención ilegal en el marco de crímenes contra la humanidad, para así salvar los problemas de retroactividad, prescriptibilidad y amnistía-; no apreció la prescripción de los delitos; no valoró debidamente la Ley 46/1977, de amnistía; se confundió al apreciar su competencia para conocer e instruir los hechos denunciados, y, por último, era notorio el fallecimiento de algunas de las personas imputadas.

En España, conforme al sistema diseñado en la ley procesal penal, sólo es posible realizar una investigación cuando existe una persona física a la que atribuir los delitos contemplados en el Código Penal y es obvio que algunas de las personas a las que Garzón incluyó como presuntos imputados ya habían fallecido. No es posible en el sistema procesal español una actividad jurisdiccional de mera indagación sin una finalidad de imposición de una penal. El Supremo destaca, en tal sentido, que los historiadores tienen su papel y los jueces el suyo; papeles que no se pueden mezclar.

Aunque Garzón, en sus autos, hablase de desapariciones forzosas en un contexto de crímenes contra la humanidad, toma el contexto como si fuera la propia calificación de los hechos y lo cierto es que, con la legislación vigente, no se podía declarar que los crímenes fueran crímenes contra la humanidad, un concepto muy posterior. Esa calificación contraría el principio de legalidad o taxatividad de la ley penal.

Respecto a la ley de amnistía, el Supremo entiende que fue un instrumento de reconciliación y en ningún caso una ley aprobada por los vencedores, detentadores del poder, para encubrir sus propios crímenes. Es una ley que está vigente y su eventual derogación correspondería, en exclusiva, al Parlamento, nunca a los jueces.

Pero aunque Garzón se equivocara, no prevaricó. No dictó una resolución injusta y, ni mucho menos, a sabiendas. Garzón fundamentó su interpretación de la legalidad — su calificación de los hechos denunciados y su competencia - en fuentes de interpretación reconocidas en nuestro ordenamiento, significativamente en normativa internacional de protección de los derechos humanos. Otra cosa es que interpretase bien el alcance y la aplicación de esa normativa y que, en todo caso, advirtiera que esa normativa ha de asumirse de conformidad con la Constitución 
Española y, en particular, con sus artículos 9.3, 24 y 25. Un tratado internacional tiene valor inferior a la Constitución, de modo que su interpretación ha de ser siempre secundum Constitutionem.

\section{UNA CONDENA CUESTIONABLE}

Aunque hay detalles importantes que habrán quedado en el tintero, el contenido de las dos sentencias del Tribunal Supremo podría resumirse de este modo. Dos sentencias vidriosas, complicadas, pero que incurren, a mi juicio, en una cierta contradicción. No se entiende bien que, enjuiciándose el mismo delito y apoyándose, en teoría, los dos pronunciamientos del Supremo en una misma doctrina sobre el tipo penal, en un caso se condene y en el otro no. Me parece más acertada la aplicación de la doctrina sobre la prevaricación en el caso de los juicios de la verdad que en el caso de la escuchas de Gürtel. En cierto modo la segunda sentencia corrige a la primera y hace una interpretación menos severa del tipo delictivo. El Supremo se enmienda la plana así mismo, consciente de que el rigor de la primera sentencia conduciría a una interpretación de la prevaricación comprometedora para la independencia judicial, pues viene a equiparar prevaricación con una interpretación de la ley distinta a la que sostenga el juez superior. La prevaricación no se deduce de una interpretación de la legalidad manifiestamente ilícita y sabida y querida como tal, sino, simplemente, de no ajustarse esa interpretación a la que un juez superior estima que es correcta. Que no se comparta una resolución judicial, no implica prevaricación. Estimar prevaricadores a todos los que no aplican la ley al modo de nuestra inteligencia es tanto como criminalizar la discrepancia jurídica. Se imponía mayor mesura, puesto que no se ha enjuiciado únicamente a un juez o una concreta resolución, sino que se ha legitimado, a la par, una interpretación excesivamente extensiva del tipo penal. Intentaré justificar más detenidamente mi discrepancia con respecto a la sentencia condenatoria del Supremo. Discrepancia fundada en tres razones ligadas a la supuesta injusticia de la resolución por la que Garzón ordenó escuchar las conversaciones de los presos con sus abogados durante su investigación de la trama Gürtel. 
Por encima de cualquier otra consideración, el tenor literal del artículo 51.2 de la LOGP, como reconoce el Tribunal Supremo, no es pacífico. ${ }^{5}$ Se presta a distintas interpretaciones. Dicho artículo establece -insisto- - que las comunicaciones de los internos con sus abogados no podrán ser suspendidas o intervenidas "salvo por orden de la autoridad judicial y en los supuestos de terrorismo". El artículo 51.5 de la LOGP añade que "las comunicaciones orales y escritas previstas en este artículo podrán ser suspendidas o intervenidas motivadamente por el director del establecimiento, dando cuenta a la autoridad judicial competente”. ¿El legislador orgánico quiso contemplar dos supuestos distintos o uno sólo? ¿Por orden de la autoridad judicial, en un caso, y por el director del establecimiento penitenciario en los supuestos de terrorismo, dando cuenta a la autoridad judicial competente, en otro caso? ¿O sólo por orden del juez y en el curso de investigaciones sobre delitos de terrorismo?

Cierto es que había jurisprudencia del Tribunal Constitucional y del Tribunal Supremo sobre el tema que aclaraba el sentido de la interceptación de las conversaciones entre internos y letrados. Esa jurisprudencia, a día de hoy, pone en claro que la ley contempla un sólo caso: por la autoridad judicial y en supuestos de terrorismo. Pero esa jurisprudencia ha variado. El Tribunal Constitucional mantuvo un criterio en 1983 que fue modificado a partir de $1994 .{ }^{6}$ Por otra parte, como acepta el Supremo, un juez puede disentir de la jurisprudencia del Tribunal Constitucional y del Tribunal Supremo siempre que el apartamiento no sea arbitrario y esté motivado. ${ }^{7}$ Lo único censurable desde la perspectiva constitucional, y en mérito a la igualdad en la aplicación de la ley, es la falta de motivación del cambio decisorio. Si hay razones de peso no conviene quedarse anclado en el respeto a la sentencia anterior pues la jurisprudencia ha de ser dinámica y no estática. La motivación es, pues, la piedra de toque.

En íntima relación con lo anterior, el Tribunal Supremo acepta - no comparte esta tesis, pero tampoco la desautoriza absolutamente- que quizá pudieran incluso intervenirse por orden judicial las comunicaciones entre los internos y sus abogados más allá de los supuestos de

5 Fundamento de derecho octavo, apartado 3, de la sentencia del 9 de febrero de 2012.

6 STC 73/1983 y las posteriores 183/1994, 200/1997 y 58/1998, ya aludidas.

7 Fundamento de derecho décimo segundo, apartado 5, de la sentencia del 9 de febrero de 2012. 
terrorismo siempre que se justifiquen los indicios delictivos contra los abogados, esto es, asegurando la necesidad y el respeto al principio de proporcionalidad de la medida restrictiva del derecho de defensa. ${ }^{8} \mathrm{Y}$ si se admite que el derecho a la defensa no es un derecho absoluto y que, por consiguiente, puede limitarse siempre que se justifique suficientemente, ¿en verdad Garzón no motivó la intervención? ¿Ni siquiera de una forma concisa o breve? ¿No ofreció siquiera unas razones mínimas del sentido de su decisión? ¿Únicamente dio cumplimiento formal de la motivación amparándose en frases sin sustento fáctico ni jurídico? Aun cuando se equivocara y pudiera haber hecho una interpretación poco o nada favorable al derecho de defensa, ¿su resolución no contenía una motivación suficiente?

Es un hecho incontestable que, en el auto por el que acordó la interceptación de las comunicaciones, Garzón se refirió a que los letrados podían estar actuando como "enlaces", aprovechando su condición para trasladar información al grupo organizado investigado; indicó con "carácter especial" las conversaciones que mantuviesen los imputados con un concreto letrado; pidió a los funcionarios de la Dirección General de Instituciones Penitenciarias que grabasen pero no escuchasen las conversaciones, de modo que sólo los funcionarios de la policía judicial podían escuchar y transcribir esas conversaciones "previniendo", en todo caso, "el derecho de defensa". Él, en última instancia, en tanto juez instructor, decidiría qué podía incidir en el derecho de defensa, de suerte que eso se borraría.

Garzón, así pues, sí ponderó, sopesó los intereses en conflicto: el interés de la justicia en la más segura represión de los delitos, por un lado, y los derechos fundamentales de los imputados - significativamente el derecho de defensa—, por otro. Interpretó, asimismo, que la intervención de las conversaciones entre presos y letrados podía apoyarse solamente en la existencia de indicios criminales respecto a los internos. Cuestión distinta es que la ponderación de Garzón fuese la más acertada; de hecho, el Tribunal Superior de Justicia de Madrid, con mejor criterio en mi opinión, anuló las escuchas. ${ }^{9}$ Pero que su moderación no fuese la más apro-

8 Fundamento de derecho octavo, apartado 7, de la sentencia del 9 de febrero de 2012.

Auto del 25 de marzo de 2010. 
piada, que incurriese incluso en violación de derechos fundamentales, no implica prevaricación.

La ambigua redacción de la Ley General Penitenciaria y la inexistencia de otra ley que regule de forma detallada la comunicación entre los imputados y sus abogados o sancione su interceptación por orden judicial proporcionan racionales espacios para la duda. Moverse en esos ámbitos inestables y problemáticos, en un contexto de vacío o insuficiencia normativa - que admite expresamente la propia sentencia condenatoria del Supremo y el auto del Tribunal Superior de Justicia de Madrid - compadece mal con la injusticia y el decidido y perverso ánimo de prevaricar que se imputa a la resolución de Garzón. El Tribunal Supremo pierde la oportunidad de abordar la cuestión de hasta qué punto, teniendo en cuenta ese marco normativo defectuoso, se debe garantizar la confidencialidad de las conversaciones del abogado con su cliente en el curso de un proceso penal. Y sin otra base que su propia convicción, los siete magistrados firmantes de la sentencia condenatoria excluyen cualquier propósito distinto al de la prevaricación, convencidos de que la cláusula de salvaguardia del derecho de defensa fue un artificio que adoptó Garzón para enmascarar su propósito delictivo.

Hay, por último, una dimensión del asunto que no puede soslayarse. La prevaricación judicial es un delito que presupone una resolución injustificable acudiendo a las reglas de interpretación comúnmente aceptadas. Siendo ello así, cabría preguntarse si puede existir prevaricación cuando la interpretación de la ley que hace la resolución controvertida ha sido compartida por otros operadores jurídicos. El Tribunal Superior de Justicia de Madrid anuló el grueso de las escuchas ordenadas por Garzón, pero esas escuchas fueron avaladas por el juez del Tribunal Superior de Justicia de Madrid que le sucedió en la instrucción, Antonio Pedreira, por las dos fiscales anticorrupción adscritas a la causa y por el magistrado de la Sala de lo Civil y Penal del Tribunal Superior de Justicia de Madrid, José Manuel Suárez Robledano, en su voto particular contrario a la anulación de las escuchas. Otros operadores jurídicos hicieron la misma interpretación. El Supremo, en la sentencia sobre los juicios de la verdad, atribuye importancia a este hecho, considerando que, si otros aplicadores-intérpretes normativos realizan la misma interpretación, no se puede apreciar prevaricación. ${ }^{10}$ Por el contrario, la sentencia condenatoria de las

${ }^{10}$ Fundamento de derecho séptimo de la sentencia del 27 de febrero de 2012. 
escuchas de Gürtel pasa de puntillas sobre el tema, lo despacha sin mayor argumentación, limitándose a decir que el aval de otros operadores jurídicos "no puede convertir en justa la decisión del juez instructor si no lo era cuando esa decisión se adoptó" 11 . Esos otros operadores jurídicos no pueden sanar la injusticia de su resolución. El tema recibe menos atención de la que hubiera merecido.

En suma, a mi juicio, Garzón se equivocó. De permitirse la intervención indiscriminada de las comunicaciones, el derecho de defensa quedaría seriamente afectado. De aceptarse lo que ordenó Garzón, se podrían interceptar las conversaciones de meros sospechosos con sus abogados sin indicio inculpatorio contra los letrados, sin ninguna finalidad de investigación concreta más allá de "pillarlos en un renuncio". Pero apreciar prevaricación en su conducta supone elevar hasta límites insospechados el tipo penal. No es infrecuente que muchos de los recursos de amparo que resuelve habitualmente el Tribunal Constitucional ex artículo 44 de la Ley Orgánica del Tribunal Constitucional tengan su origen en una grosera violación de derechos fundamentales imputable directa e inmediatamente a un órgano judicial a partir de una interpretación de la ley desfavorable a los derechos fundamentales, a veces incluso contraviniendo doctrina consolidada del Tribunal Constitucional y del Tribunal Europeo de Derechos Humanos sin que se motive el apartamiento de esa doctrina. ${ }^{12}$ La condena al juez Garzón es objetable - aunque no creo que prospere el anunciado recurso de amparo pues no se dan los requisitos para apreciar vulneración de la igualdad en la aplicación judicial de la ley ni vulneración del derecho a la tutela judicial efectiva-. Y ello — reiterosin negar que Garzón incurriese en un error. Se equivocó, incluso gravemente, pero no prevaricó. Garzón, ni escrupuloso garante de los derechos humanos ni obsesivo prevaricador.

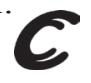

11 Fundamento de derecho décimo primero, apartado 5, de la sentencia del 9 de febrero de 2012.

12 Así, entre otras, SSTC 268/2006 y 59/2011. 